\title{
CFD ANALYSIS ON JET NOISE REDUCTION USING FAN FLOW DEFLECTORS
}

\author{
Sivaraman S', Dhanush S.A², Bhavani Sai Sujith V³ , Ashwin $\mathrm{S}^{\mathbf{4}}$, Balaji $\mathbf{M}^{\mathbf{5}}$ \\ ${ }^{1}$ Assistant Professor - Hindusthan College of Engineering and Technology, Coimbatore , Tamilnadu \\ 2,3,4,5 Student- Hindusthan College of Engineering and Technology, Coimbatore, Tamilnadu \\ Corresponding Author: Sivaraman S
}

\begin{abstract}
Fan flow deflection for jet noise reduction was applied to subscale nozzles simulating the geometry and exhaust conditions of separate-flow turbofan engines. Two types of deflectors were investigated, one comprising two pairs of vanes internal to the fan duct and the other consisting of a wedge positioned outside the fan duct. The noise reduction achieved by the vanes was strong in the downward direction and moderate in the sideline direction. The wedge generated significant attenuation in both directions. Here the vane deflector going to be used on fan duct. When the flow passes through the nozzle the turbulent eddies can be generated more. While place a vane deflector on the fan duct, the vane deflectors reduce the TKE on the underside of the jet and increase it on the topside of the jet. There is a significant correlation between the decrease of the TKE near the end of the potential core and the reduction in overall sound pressure level in the direction of peak emission and the flow becomes streamlined flow and then the noise can be decreased.
\end{abstract}

\section{INTRODUCTION}

For the past five or so years, a great deal of effort has gone into research and development aimed at decreasing the noise problem associated with the jet transport. As long ago as 1953 it was felt that a noise reduction of about $15 \mathrm{db}$ outward through would be required to make the jet transport comparable to propeller driven airplanes. Aircraft noise has been an issue of enormous environmental, financial, and technological impact.

Most commercial aircrafts are equipped with turbofan engines due to their capability of providing higher performance and lower noise when compared with turbojet engines. Dominant noise sources of turbofan engines are from the fan (including the stator) and the exhaust (also referred to as the jet).

The noise produced in these two areas during take off and landing has a profound impact on the communities surrounding the airports. Several emerging technologies for jet noise reduction in turbofan engines have demonstrated potential for improving the noise metric in air-breathing jet propulsion systems.

\section{JET NOISE REDUCTION TECHNIQUES}

Jet exhaust is one of the dominant noise sources that dramatically increases with throttle push from modern turbofan engines. Jet noise can be attributed to the turbulent mixing of the hot jet exhaust (core), bypass stream (fan), and ambient air; therefore, optimizing how these three streams mix will significantly reduce its intensity. In 1996, a concept that utilized chevron nozzles was tested by NASA.

The nozzles allowed the core and bypass flows to mix in a way that reduces low frequency mixing noise from highly turbulent flows. NASA studied the amount of EPNL reduction for the following nozzle configurations: chevrons installed only on the fan exhaust, core exhaust, and on both. Greater EPNL reduction was obtained when the chevrons were simultaneously on both the fan and core exhaust nozzles.

\section{PROBLEM STATEMENT}

The focus of this work is on improving the current understanding of the physical mechanism responsible for noise suppression in asymmetric subsonic and supersonic dual stream jet configurations. The jets under discussion here are referred to as asymmetric because they have offset primary and secondary streams. The primary and secondary streams represent the core and bypass exhausts, respectively, of turbofan engines.

Offset stream nozzles include eccentric configurations and arrangements with deflection of the fan stream. These configurations alter the mean flow field of the jetplume, concentrating the low-speed fan flow underneath the core stream, thus reducing downward and sideward noise emissions with respect to the baseline coaxial jet. The fundamental principle is reduction of the turbulent kinetic energy of turbulence that causes intense downward noise. 
International Journal of Innovative Research in Electrical, Electronics, Instrumentation and Control Engineering

\author{
Impact Factor 7.047 Vol. 10, Issue 1, January 2022 \\ DOI: 10.17148/IJIREEICE.2022.10119
}

This is achieved by concentrating some of the quieter fan flow underneath the noisy core stream of a turbofan engine. The re-orientation of the fan flow is achievable using offset nozzles or fan flow deflectors. This investigation seeks to optimize the implementation of fan flow deflection for jet noise suppression. The design objective is to maximize reduction of noise perceived by the community while minimizing aerodynamic losses caused vane deflector

\title{
4. METHODOLOGY
}

Despite identification of jet noise as an important byproduct of the newly invented jet engine (Morley 1939), and as an impediment to the incipient commercial jet aircraft industry in the 1950s (Lighthill 1952; Westley \& Lilley 1952; Lassiter \& Hubbard 1952; Lighthill 1954; Lassiter \& Hubbard 1956), a completely satisfactory description of jet noise that is, of the noise produced by the turbulent exhaust gases of a jet engine| has proven elusive.

Two primary reasons for this difficulty are the lack of a universally agreedupon theory of noise generation in turbulent owes and the challenge in taking experimental measurements in (often heated) high-speed jets.Regardless, significant progress has been made on some of the theoretical descriptions of jet noise (Lighthill 1952, 1954; Lilley 1974; Goldstein 2003, to name but a few) and in its experimental characterization (Davies et al. 1963; Bradshaw et al. 1964; Tanna 1977a,b; Viswanathan 2004, for example).

However, only recently have there been successful attempts at the numerical prediction of jet noise from principles using large-eddy simulation (LES) and direct numerical simulation (DNS). Much of the current jet noise work originates at the Center for Turbulence Research through its associated students or post-doctoral fellows (Boersma \& Lele 1999; Constantinescu \& Lele 2001; Freund 2001; Jansen et al. 2002; Bodony \& Lele 2005b).

The above mentioned studies have also been quite useful in establishing numerical databases for the continued exploration of noise source processes, both in general and as specially applies to jets. This report documents some of the current e_orts underway at CTR that are relevant to jet noise prediction and to its understanding, including both studies that are well documented and those that are in their early stages.

\section{a. Fan Flow Direction}

Several years ago experiments at University of California- Irvine using eccentric dual-stream jets with a normal velocity profile showed considerable noise reduction in the direction of the thickened secondary (outer) flow. The jets were highspeed, and the bypass ratios were small. Recently, the noise reduction trends observed in those experiments were verified in a larger rig at NASA Glenn Research Center.

Other researchers have independently observed similar benefits of offset coannular nozzles. The concept of offset nozzle flows is an intriguing prospect for reducing turbulent mixing noise in high-bypass separate-flow turbofan engines used on commercial jetliners. Eccentric or severely offset nozzles are probably not viable because of the drastic redesign of the nacelle and the messy flow path in the outer nozzle. The physical mechanisms of noise reduction in offset jets are probably very complex and multifaceted. The experimental evidence so far indicates that, using offset nozzles or FFD, there is always a reduction of peak noise in the azimuthal direction of the maximum thickness of the fan flow. The off-set method is called Fan Flow Deflection method (FFD).

\section{b. $\quad$ A wedge shaped deflector}

The wedge deflector which is located at the top of the nozzle. Both devices can be internal or external to the bypass duct, although for commercial applications it is strongly preferred that the vanes be internal to avoid shock losses. The deflectors have been tested in "classic" laboratory nozzles with parallel exit flow lines and in "realistic" nozzles with convergent flow lines characteristic of turbofan engines. Vanes provide noticeable noise reduction for both types of nozzles, although noise reduction in the realistic nozzle was superior to that in the classic nozzle.

\section{DESIGN ANALYSIS}

\section{a. Introduction}

Several years ago, GE Aircraft Engines realized that with the expected increased stringency of Stage 4 noise regulations, the continued thrust growth of engine families, and increasing environmental pressures, jet noise would become a restricting factor in aircraft operations. The turbofan engine is the most efficient propulsion system for aircraft traveling at high subsonic cruise speeds. Most commercial aircraft travel at a cruise Mach number of $\mathrm{M}=0.85$ (564 mph, 35,000 $\mathrm{ft}$ altitude) so the turbofan engine is widely used. The General Electric GE90 model, which is currently the world's most powerful engine and is used on the Boeing 777 airliner. New composite material technologies have been incorporated into the design of this engine adding to its improved efficiency and power capabilities from previous models.

b. My Design

As discussed above, the fan flow deflection method is going to be used for my design. There are two deflectors used in this investigation. The purpose of the airfoilshaped vanes and wedge-shaped deflectors is to create asymmetry in a dual- 
International Journal of Innovative Research in Electrical, Electronics, Instrumentation and Control Engineering

Impact Factor 7.047 ㄷ Vol. 10, Issue 1, January 2022

DOI: 10.17148/IJIREEICE.2022.10119

stream jet by imparting an aerodynamic force on the secondary fluid, thereby diverting some of the secondary flow to the side and underneath the highspeed primary jet. The asymmetry that results is in the form of a thickened low speed fluid in the hemicylinder underneath the jet centerplane, targeting the dominant noise sources near the end of the primary potential core. Below Figures shows the general concepts of the Fan Flow Deflection Method(FFD) when two deflectors are used.

\section{c. The Vane Deflector}

The vane deflector is used to tilting the flow downwards to some degree and reduces the noise in the peak emission. The vane deflector is the airfoil shaped one.so I used NACA 0012 for the vane. The coordinates for the NACA 0012 is given in the table below. The chord of the vane is $4 \mathrm{~cm}$. The axial location of trailing edge relative to exit of fan nozzle which is nothing but the length between the trailing edge of the nozzle to the edge of the secondary nozzle is $2 \mathrm{~cm}$. The geometry parameters of vanes is given in the below figure.

\subsection{Introduction}

\section{DESIGN AND IMPLEMENTATION}

The convergent nozzle has good acoustical benefits than the parallel nozzle.so here we are going to use the convergent nozzle and will be analyzed by the CFD. From the nozzle geometry ANSYS -CFX software is used because of this high performed process. The dimension has taken from the journals and reference papers. The nozzle assemblies includes three elements: secondary (fan) nozzle, primary (core) nozzle, and center plug. The purpose of the airfoil-shaped vanes and wedge-shaped deflectors is to create asymmetry in a dual-stream jet by imparting an aerodynamic force on the secondary fluid, thereby diverting some of the secondary flow to the side and underneath the highspeed primary jet

\subsection{Ansys CFD}

ANSYS CFX software is a high-performance, general purpose fluid dynamics program that has been applied to solve wide-ranging fluid flow problems for over 20 years. At the heart of ANSYS CFX is its advanced solver technology, the key to achieving reliable and accurate solutions quickly and robustly.

The modern, highly parallelized solver is the foundation for an abundant choice of physical models to capture virtually any type of phenomena related to fluid flow. The solver and its many physical models are wrapped in a modern, intuitive, and flexible GUI and user environment, with extensive capabilities for customization and automation using session files, scripting and a powerful expression language.Automotive in-cylinder flow model with ANSYS CFX Software (Courtesy of BMW) But ANSYS CFX is more than just a powerful CFD code.

\subsection{Convergent Nozzle}

The convergent nozzle is a scaled-down version with the dimensions given in the It has convergent exit flow lines and a geometry that is representative of actual separateflow turbofan engines. The dimensions which are used in the design is given in the table below

\section{PERFORMANCE ANALYSIS}

\subsection{Introduction}

The computational study of the dual-stream exhaust of a turbofan engine with noise suppressing deflectors installed in the fan stream. The focus is on validating the computational code, extracting turbulent kinetic energy (TKE) trends, and connecting those trends to the measured noise reduction. We consider two operating conditions, a "cold" condition at which mean flow surveys were conducted and against which the code was validated; and a "hot" condition. For both conditions, the vane deflectors reduce the TKE on the underside of the jet and increase it on the topside of the jet.

There is a significant correlation between the decrease of the TKE near the end of the potential core and the reduction in overall sound pressure level in the direction of peak emission. This study will provide a basis for the further use of CFD in the investigation of noise reduction and performance of fan flow deflected supersonic turbofan engines.

Nozzle with double pair vanes at $10^{\circ} \mathrm{AOA}$

TKE counter diagram double pair vanes at $10^{0} \mathrm{AOA}, \mathrm{TKE}=3.2 \mathrm{~m}^{2} / \mathrm{s}^{2}$ 


\section{DETERMINATION OF OVERALL SOUND PRESSURE}

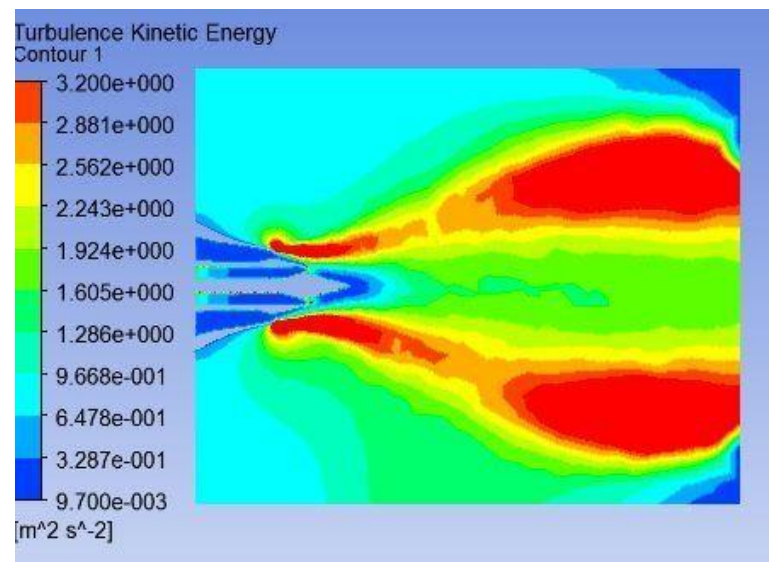

\subsection{Overall Sound Pressure Level (OASPL)}

- The acoustic pressure at a point in space where the microphone or listener's ear is situated. It can be expressed in unit of pressure or in decibels.

- The sound pressure level or overall sound pressure level is calculated from the formula. $\mathrm{dB}=20 \log \mathbf{P}$ Pref ....(7.4) where $\mathrm{P}$ - Pressure fluctuation (or) Pressure variationType equation here. P ref - pressure reference. Normally it's about $2 \mathrm{x} 10-5 \mathrm{~Pa}$.

- The above equation is simplified as $\mathrm{dB}=10 \log (\mathbf{1 0}-\mathbf{5})$,which is going to be used in this project.

\section{RESULTS AND DISCUSSION}

I have conducted an investigation of the effect of baseline nozzle shape on the acoustic performance of fan flow deflectors for turbofan noise suppression. A coaxial nozzle with parallel flow lines and a realistic coaxial nozzle with convergent flow lines were overviewed.

For all types of comparisons and all deflector arrangements, the nozzle produced superior acoustic performance. Importantly, the results shed more light on the 62 desired shape of the mean flow field for effective noise suppression. The following general observations can be inferred from the results:

i. Internal vanes in a nozzle with convergent flow lines displace flow downward and in the sideline direction, hence reducing TKE in those directions. Noise reduction in the direction of peak emission is substantial.

ii. $\quad$ ii. The computations also indicated that over the entire jet plume the turbulent kinetic energy in the hot jet was lower than the cold jet. When the axial distance was non-dimensionalized by the potential core lengths of the hot and cold jets respectively the velocity profiles almost collapsed on the same curve, indicating the physical elements of the jet are reasonably consistent regardless of the temperature.

iii. The turbulent kinetic energy results for the fan flow deflection configurations determined using CFD showed a general decrease in $\mathrm{k}$ on the underside of the jet and a corresponding increase in $\mathrm{k}$ on top of the jet. It is notable that the location of peak turbulent kinetic energy occurs close to the end of the potential core for all cases studied.

iv. A preliminary correlation was established between the peak overall sound pressure level (OASPL) and the turbulent kinetic energy in the jet plume.

v. This study provides a solid framework for the continuing investigation of noise reduction in supersonic turbofan engines implemented with fan flow deflectors. Using this computational code it will be possible to determine aerodynamic properties of the deflectors and the corresponding mass and thrust loss that results from their implementation. Additionally it will be possible to perform an airfoil optimization scheme to determine the optimal airfoil shape and placement to achieve the highest noise reduction for low thrust loss.

\section{REFERENCES}

1. Papamoschou, D. and Shupe, R.S., "Effect of Nozzle Geometry on Jet Noise Reduction using Fan Flow Deflectors," AIAA Paper 2006-2707, presented at the 12th AIAA/CEAS Aeroacoustics Conference, Cambridge, MA, May 8-10, 2006. 2. Papamoschou, D., and Debiasi, M., "Directional Suppression of Noise from a High- Speed Jet," AIAA Journal, Vol. 39, No. 3, 2001, pp. 380-387.

3. Zaman, K. B. M. Q., "Noise- and Flow-Field of Jets from an Eccentric Co-annular Nozzle," AIAA Paper 2004-0005, Jan. 2004. 
International Journal of Innovative Research in Electrical, Electronics, Instrumentation and Control Engineering

Impact Factor 7.047 ㄷ Vol. 10, Issue 1, January 2022

DOI: 10.17148/IJIREEICE.2022.10119

4. Harper-Bourne, M., "Physics of Jet Noise Suppression," Proceedings of Jet Noise Workshop, CP 2001-211152, NASA, Nov. 2001.

5. Papamoschou, D., "Engine Cycle and Exhaust Configurations for Quiet Supersonic Propulsion,” Journal of Propulsion and Power, Vol. 20, No. 2, 2004, pp. 255-262.

6. Papamoschou, D., "New Method for Jet Noise Suppression in Turbofan Engines," AIAA Journal, Vol. 42, No. 11, 2004, pp. 2245-2253.

7. Tam, C. K. W., “Jet Noise: Since 1952,” Theoretical and Computational Fluid Dynamics, Vol. 10, Nos. 1-4, Jan. 1998,pp. 393-405.

8. Saiyed, N. H., Mikkelsen, K. L., and Bridges, J. E., "Acoustics and Thrust of Separate-Flow High-Bypass-Ratio Engines," AIAA Journal Vol. 41, No. 3, 2003, pp. 372-378.

9. Doty, M. J., and McLaughlin, D. K., "Acoustic and Mean Flow Measurements of High-Speed, Helium-Air Jets," International Journal of Aeroacoustics, Vol. 2, Nos. 3-4, 2003, pp. 293-333.

10. Murayama, T., Papamoschou, D., and Liu, F., "Aerodynamics of Fan Flow Deflectors for Jet Noise Suppression," AIAA Paper 2005-0994, Jan. 2005.

11. Papamoschou, D., "Acoustic Simulation of Hot Coaxial Jets using Cold Helium- Air Mixture Jets," AIAA Paper 2005-0208, Jan. 2005; also Journal of Propulsion and Power.

12. Tam, C. K. W., "Influence of Nozzle Geometry on the Noise of High- Speed Jets," AIAA Journal, Vol. 36, No. 8, 1998, pp. 1396-1400.

13. Savitzky, A., and Golay, M. J. E., "Smoothing and Differentiation of Data by Simplified Least Squares Procesures," Analytical Chemistry, Vol. 36, No. 8, 1964, p. 1627.

14. McGowan, R. S., and Larson, R. S., "Relationship Between Static, Flight and Simulated Flight Jet Noise Measurements," AIAA Journal, Vol. 22, No. 4, 1984, pp. 460-464.

15. Murakami, E., and Papamoschou, D., "Eddy Convection in Supersonic Coaxial Jets,” AIAA Journal, Vol. 38, No. 4, 2000, pp. 628-635.

16. Bass, H. E., Sutherland, L. C., Zuckerwar, A. J., Blackstock, D. T., and Hester,"Atmospheric Absorption of Sound: Further Developments," Journal of the Acoustical Society of America, Vol. 97, No. 1, 1995, pp. 680-683.

17. Noise Standards: Aircraft Type and Airworthiness Certificiation, Federal Aviation Regulations Federal Aviation Administration, Jan. 2001, Pt. 36.

18. Society of Automotive Engineers Aerospace A21 Committee, "Prediction of Lateral Attenuation of Airplane Noise During Takeoff and Landing," Society of Automotive Engineers Information Report SAE AIR-1751, Mar. 1981.

19. Tanner, M., Determination of Base Drag with Application to the Near Wake of Wedges, Nr. 31, Mitteilungen aus dem Max-Planck Institut für Strömungsforschung und der Aerodynamischen Versuchsanstalt, Max- Planck Institut, Göttingen, 1964.

20. Narayanan, S., Barber, T. J., and Polak,D. R., "High Subsonic Jet Experiments: Turbulence and Noise Generation Studies,"AIAA Journal,Vol. 40, No. 3,2002, pp.430-437.

21. Zaman, K. B. M. Q., and Papamoschou, D., "Effect of a Wedge on Coannular Jet Noise,” AIAA Paper 2006-0007, Jan. 2006.

22. Papamoschou, D. and Nishi, K.A., "Turbofan Jet Noise Reduction Via Deflection

of the Bypass Stream," AIAA Paper 2004-0187, presented at the 42nd AIAA Aerospace Sciences Meeting, January 2004, Reno, NV.

23. Papamoschou, D. and Nishi, K.A., "Jet Noise Suppression with Fan Flow Deflectors in Realistic-Shaped Nozzle," AIAA Paper 2005-0993, presented at the 43rd AIAA Aerospace Sciences Meeting, January 2005, Reno, NV.

24. Murayama, T., Papamoschou, D., and Liu, F. "Aerodynamics of Fan Flow Deflectors for Jet Noise Suppression," AIAA Paper 2005-0994, presented at the 43rd AIAA Aerospace Sciences Meeting, January 2005, Reno, NV.

25. Birch, S.F., Khritov, K.M., Maslov, V.P., Mironov, A.K., and Secundov, A.N.,

"An Experimental Study of Flow Asymmetry in Co-axial Jets," AIAA Paper 2005-2845, presented at the 11th AIAA/CEAS Aeroacoustics Conference, May

2005, Monterey, CA

26. Papamoschou, D. Vu, A., and Johnson, A.J., "Aerodynamics of Wedge-Shaped Deflectors for Jet Noise Reduction," AIAA Paper 2006-3655, presented at the 24th AIAA Applied Aerodynamics Conference, June 2006, San Francisco, CA. 27. Georgiadis, N.J. and Papamoschou, D., "Computational Investigations of High-

Speed Dual Stream Jets," AIAA Paper 2003-3311, presented at the 9th AIAA/CEAS Aeroacoustics Conference, May 2003, Hilton Head, SC.

28. Dahl, M.D. and Morris, P.J., "Noise from Supersonic Coaxial Jets, Part 3: Inverted Velocity Profile,” Journal of Sound and Vibration, Vol.200, No.5, 1997.

29. Papamoschou, D. "Acoustic Simulation of Hot Coaxial Jets using Cold Helium- Air Mixture Jets," AIAA Paper 20050208, Jan. 2005. 30. Murakami, E., and Papamoschou, D., "Eddy Convection in Supersonic Coaxial Jets,” AIAA Journal, Vol. 38, No. 4, 2000, pp. 628-635. 